\title{
Glocalised-television content: Interaction with local cultures and impact on audience perceptions
}

Shamala R.

Central University of Tamil Nadu, India

Devadas M.B.

Independent Researcher

Francis P. Barclay

Central University of Tamil Nadu, India

DOI: 10.30547/worldofmedia.1.2019.2

\begin{abstract}
Glocalisation as a fallout of globalisation has received a lot of theoretical and empirical attention in the past few decades. Though the concept of globalisation was much evident and propagated through television in the streaming of foreign content on local networks, that content soon had to be given local flavours to captivate the local audience. Examining whether the global content just got a local twist or propagated an amalgamation amounting to novel cultures is the primary focus of the present study. Though it is evident that glocalised television content (intentionally or unintentionally) brought about significant changes in mass attitude, lifestyle and behavior, it needs to be empirically analysed and understood. Using a survey of 200 Indian-urban youth, the study measures the cultural impact of glocalised television content. This apart, the study analyses content and growth of television channels, viewing patterns of urban youth, the motivation behind using the medium, degree of attitudinal change and also the perceptional impacts on local cultural dimensions.
\end{abstract}

\section{Keywords}

Globalisation, glocalisation, television, cultural impact, attitudinal change.

\section{Introduction}

'Globalisation' has been a wide-spread concept since the 1990s. The process has brought in its folds multiple connotations, which has powerful cultural

Corresponding author:

Shamala R., Department of Media and Communication, Central University of Tamil Nadu, Thiruvarur, CUTN Bridge, Neelakudy, Tamil Nadu 610005, India.

Email: shamala@cutn.ac.in 
dimensions. The 'World Culture Theory' interprets globalisation in the intercultural perspective. The profounders of the theory claim that globalised world is of course an integrated world, but the interdependence is amidst an ambience of cultural heterogeneity. The cognitive dissonance theory further accentuates the existence of sub-contrasts. The society and the prevailed culture play a vital role in the process of true interpretation of the term. The rises of multinational media conglomerates have popularised the term 'globalisation'. Television played a complicit role with an indefatigable spirit to popularise the essence and spirit of globalisation. Television has transformed globalisation into glocalisation in order to cater for the local media, the emergence of transnational channels cable television and liberation privatisation and globalisation in to the antique teeming land of India. However, the concept of globalisation failed to strike a chord among the people at its initial stages. India unlike any other country has its own archaic grandeur and culture. The 'global culture' had much less effect on the 'local culture' of India. Thus, the concept of convergence was an unrealizable dream at the initial stage of its emergence in India. However, the emergence of cable television brought a paradigm shift soon. In order to overcome the barriers that hinder the spread of 'global culture', 'glocal culture' added some local flavours. The television was able to accelerate a slow and steady cultural change among the people of India especially the media savvy youth. Hereafter, the amount of new information and communication technology accompanied with liberalization of Indian economy, this paved the way for increased household accessibility of television by the number of channels. Soon India has become the third largest television market in the world. The television channels functioning in India has been trying to make their content and presentation at par with global standards without losing the local spirit. The language localization of global channels such as MTV, Animal Planet, Discovery, and Pogo are only a few examples.

\section{Globalisation impact on culture}

In this multicultural world the emergence of global culture is forcing forward new ways of simplifying things. Culture is a complex term with different meanings. Culture varies from place to place and person to person. The globalised culture may have a very little effect on the prevailed culture in India. In fact, the complex cultural fabric of the nation dictates the lifestyle of its citizens. However, since a long time ago, there have been two different coexisting cultures in India the traditional practice and the transfixed one. The global culture had to cope with local needs and transformed into glocal culture at a certain stage. When the 'globalisation' became 'glocalisation' with its multi directional effects, the 
striking rate went high, and globalisation was thus able to bring a cultural change. Tomlinson (1999) says that globalisation will lead to a single global culture effect of connectivity in terms of the economic sphere. This cultural transfusion was intentional or unintentional. Media by its inherent style of functioning dissipated the globalised culture with the needs and aspirations of the people. An analysis of the content of the channels gives an idea of the perfect cultural change amounting from the medium. Globalisation was able to create a new culture by revitalizing the existing culture. Thus, local elements coexist, but the cultural ones encounter across the frontiers and create a new kind of cultural fusion hybridity. Globalised television has become a cultural theme, a motivational or inspirational medium to accelerate cultural shift. This cultural shift can have either a positive or a negative effect. This study makes an attempt to look into the impact of globalised television on youth, as they are the prime seers of this medium.

\section{Glocalisation and television}

The term glocalisation is defined by the researchers in different ways. Intuitively, glocalization is a process where globalisation adapts itself to cater for the local needs. It is otherwise a perfect blend of globalisation and localization. The globalisation concept is of a great importance to a country like India which has bounded with many cultural fashions and traditions. Glocalisation emerged as an alternative to globalisation when it failed to cater for the needs of the local people. Globalisation showed its light in the early 1990s. The advent of cable television and the emergence of transnational television in India accelerated growth and development of globalisation, but the process was still in the stage of infancy and growth. This is because of the various limitations that India faces like the conventional culture which is complex and divided at both local and national levels. India had started witnessing a perfect shift toward globalisation by the end of 2005. This was because of the penetration of television industry. The television industry was the dominant entertainment media industry in India at the end of 2005 with a share of around $42 \%$. Western music channels also by then started ruling the globe and became a powerful force of cultural exchange (Jones, 2005). The mushrooming channels further intensified the competition among the channels. Each channel wanted to raise their TRP. In this scenario television broadcasting companies were adopting the strategies of globalisation and regional based customization to improve their viewership and this increased the return on investment and the format of global integration of programmes penetrating to every household. Many media houses captured these ideas (Waisbord, 2004). A number of Western serials, reality shows were 
adapted and Indianized to meet the local culture, religious beliefs, and other ethnic characteristics of the regional viewers of India. Though this trend of foreign invasion of Indian culture was criticized, yet it managed to create its own cultural space as well as intervene in the national cultural landscape, with more deregulation and foreign investment, media industry kept the landscape expanding. Adding the local flavour to the global programmes has propelled the overall television scenario in India. Such a trend can be considered a strong manifestation of globalisation.

\section{Understanding of culture}

'Culture' is a complex term, and understanding its perfect meaning is a difficult task. According to Kroeber, 'culture' is an intervening variable between human organism and environment; socialist T. S. Eliot in his work 'Notes towards definition of culture' relates culture to individuals, social groups and whole societies, though their interdependence is such that cultural health requires an overlapping and sharing of interests by participation and mutual appreciation.

Great Hofstede, a cultural anthropologist, defines it as 'the collective programming of the mind that distinguishes the members of one group or category from those of other'. Another sociologist Bogardus says that 'culture is the way of belief of a group'.

In a nutshell culture can be understood as 'a system of shared beliefs, values, customs, behaviors, and artifacts that the members of the society use to cope with the world transmitted from one generation to another'. With the understanding of these definitions we can conclude that culture is a set of certain behavior patterns that we are living with consciously or unconsciously, so a large part of it is unconsciously incorporated in our behavior patterns and lifestyle.

Culture develops from simple (in the beginning) to complex (in later). It is worth having a discussion on the other two important topics which fall under the culture - cultural diffusion and cultural theme. Cultural diffusion can be defined as the spread of culture from one area to another. This spread can be conscious or unconscious. The culture does not flow from one area to another; it is transmitted from one generation to another. Mass media and communication technologies play a key role in this process - for instance, radio and television have been the primary instruments.

Cultural theme is defined as the inspiration or motivational instrument that can direct an individual to acquire the particular culture or its elements. Television is one of the powerful cultural themes. Television is acting as catalyst in the process of cultural transmission from one place to another. In this process some adaptation may happen in the original cultural form in order to cope with 
the existing beliefs and culture of the place where the cultural acceleration happens. Therefore, the globalised television in India acts as a cultural theme and creates a cultural Coup d' tat.

Cultural Coup d' tat is defined as a slow and steady penetration of alien cultural elements into a prevailed cultural fabric and accelerate a cultural change which finally result the predominance of the alien culture over the existing culture resulting a mix culture. The intrusions of alien culture into the local culture either decline or incline the existing cultural forms. The degree of cultural change emerges as a result of cultural Coup d' tat and depends on the inclination of the victims towards the cultural theme. The study makes an attempt to explore whether globalised television (the cultural theme) is able to create cultural Coup d' tat. In other words, as a case in point, there can be a person, who is exposed to television, gets enticed by a programme and then starts imitating the behavior, dress code or life style he sees on TV.

\section{Television and globalisation in India}

By the LPG policy government, the television industry has come out from the clutches of Doordarshan in the early 1990s. The early DD dominated era on Indian television went for a small change in the 1980s with infusion of entertainment genres including soaps, films, and film related programming. However, the real transformation came in 1992 when liberalization allowed the entry of transnational players like Star TV.

The Indian television was owned by government channels in all 26 dialects to a multi-channel global media market till 1991 (Rodrigues, 2010). In the falloff 1991, as hundreds of unregulated cable TV operations flourished in urban areas, new channels began appearing on Indian televisions courtesy of ZTV, MTV, and all day sports channels for cricket hungry, South Asian fans, two entertainment channels carrying a heavy dose of American programming, and BBC world, which the British Broadcasting corporation launched, undoubtedly, as its answer to CNN. Practically overnight millions of Indian Television viewers, long woo to DD's staid educational programming and dramas based on Indian mythology, found themselves turning into the likes of 'Baywatch', 'Dallas' and 'Dynasty'. In the land where kissing has never been allowed in national movies or television programming TV viewers could experience the 'sex and violence' culture long decried even in the West.

When Rupert Murdoch expanded the Star Network in India, his agenda was based on a strategic commercial goal, however the initial stint of Star Network to the top slot. Understanding the cultural connotations, they started a swift change in their presentation style. There has been no looking back since then. 
Adding the local flair to the global ideas has propelled the overall television scenario in India.

In early 1999, three were 20 million cable households in India, including at least the million multiple TV households and the reach of television was expanding fast. The next in the Indian television industry was expected to arrive in the country by early 2000 in the form of Direct to Home (DTH) television planned by Rupert Murdoch's News Corporation and Indian broadcasters. The youth in India was carried away by the Western style of MTV channel 1996, stated in Juluri (2002).

Television industry was the dominant entertainment media industry in India at the end of 2005 with a share of around $42 \%$ and it was expected to grow by around $10 \%$ annum till the end of 2011. In this scenario television broadcasting companies were adopting the strategies of globalisation and regional based customization to improve both viewership and return to investment. The songs mixed in Hindi and English became Hinglish (mix of global and local languages) which started attracting everyone and gained huge popularity on TV chartbusters (Bakshi \& Sarkar, 2015). Indian television industry witnessed a paradigm shift after globalisation as from on TV channels to hundreds of them competed with each other to catch the viewer's attention, there were umpteen opportunities to play with the content and serve versatility.

\section{The Karnataka scene}

Doordarshan DD Chandana is the state TV channel in Karnataka. There are more than 100 channels available in Bangalore city including the transnational players like SONY, STAR world, STAR plus, STAR movies, Star news, MTV [V] music, Zee cinema, Zee Drama. Fashion TV, BBC world, CNN, Cartoon Network and so on. The major local television channels available in Bangalore city are Udaya TV, Udaya news, U2, E TV, TV9, Kasturi, Suvarna, and so forth. Many of the local channels are programming in global standards. Many of the global networks have bought the local channels. For example, the STAR network owns the Suvarna Channels. The content of these TV channels was global in spirit and local in characteristics. This is a spate of reality shows on the south Indian television that are based on Western concepts. The ideas are borrowed but the form and presentation is completely localized. Such a trend can be considered a strong manifestation of glocalization.

\section{Review of literature}

The review of related literature has indicated that very few studies of impact of globalised television on youth are reported in India. However, studies on media 
consumption in the form of media habits has been part of many studies and reported well in India. A number of studies have shown that demographics like age, income, occupation and sex of the audience do have profound influence on their media consumption pattern.

MC Nelly (1968) in their study on functional aspects reports that media usage plays a prominent role in the diffusion of international information, but such media behavior does not necessarily have a simple cause and effect relationship general or specific knowledge. Allen (1968) in their study on Negro residence reports that they view television extensively because it provides fantasy and entertainment programmes.

Rubin (1985) in his study on college students use of daytime television soap operas states that uses and gratifications researchers have found that motives for watching television and its programmes are interrelated both ritualized and instrumental issues have been identified.

A number of studies attempt to explore the concept of a new globalised culture, the byproduct of globalisation. Giddens (1990) names it the dialectic of the local and global, where globalisation has to be understood as a dialectical phenomenon in which events at one pole of distanced relations often produce divergent or even contrary occurrence at another, so the connecting of the local and global has been tied to a profound set of transmutations in the nature of modern life. Then structural hybridization is a factor in the reorganization of social spaces or the emergence of new practices of social cooperation and competition, which can be also new trans-local cultural expressions (Pieterse, 1995). Kirth states that the 1990s witnessed the rise of hybridity as a multidisciplinary concern over the fragmentation and fusion of cultural forms. Also, in this scenery the media groups develop a tendency of hybridity mass media cross-breeding cultural signs, values, and styles to reach transnational audiences.

To understand the transnational and global connotations of culture, A. Appadurai has divided the flow of culture into five scapes - ethnoscape, technoscape, financescape, mediascape, and ideoscape. According to this system, mediascape refers to the dissemination and flow of images and information by print and electronic media. P. Vijayalakshmi in 'Foreign television and Indian youth' gives ideas about the influence of global television on Indian youth. According to her, the televisions in Asia has been transforming since the introduction of cable and satellite cross border channels since 1991. The MTV strategy for entry into foreign countries like India based on the policy that localized programmes and localized business were made more successfully than following standardization. This directly results in the adding of local flavour to global ideas (Juluri, 2002). 


\section{Objectives and methodology}

The present study intends to shed light on the social and cultural implications of globalised television. The main objective of this research paper is to find out the television viewing pattern of the urban youth, to find out the motive behind using this medium, to determine the degree of attitudinal change amounting from the medium, to analyse the cultural impact of globalised television on urban youth, to examine the cultural impact of the medium.

In the present study, the independent variables are age, gender, educational qualifications. Average monthly family income and occupation of the respondents are the measure. The dependent variables - media usage and gratification frequency of television usage, preferences over various types of channel, types of programmes preferred watching, preference over foreign and Indian channels, preference of respondents over various channel; effects amounting from the medium - preference of food items seen on TV, preference of dress/apparel seen on TV, imitation of hair style/ mannerism seen on TV, preference of branded products, motivational medium behind choosing a brand; Purpose behind using the medium - purpose of TV viewing. The survey questionnaire was served to 200 respondents chosen through convenient sampling technique. The target sample of the present research is youth generation in the Bangalore city. The youth in this study is identified as people from 18-35 age group based on the definition given by Ministry of Youth Welfare Government of India. The samples were divided into four parts of Bangalore city - North, West, East, and South. A convenient sampling method was used to collect the data from each zone where the colleges and the students should be interested in participating in the research. The data collected from the survey was then analyzed using the percentage method.

\section{Findings and analysis}

The findings obtained from the analysis of the data collected by questionnaire are explained below as four sections.

\section{SECTION-1}

\section{Demographic profile of the respondents} Age, gender, educational qualifications

Average monthly family income and occupation were the independent variables concerning the demographic and disciplinary affiliations of the respondents. Data were collected from 200 respondents. Among the respondents there were 146 males and 54 females.

Age: the majority of the respondents 93 out of 200 fell in the age group of 2328 years followed by the $18-23$ which has 64 respondents, while 32 respondents are 
between 28 and 33, 11 are aged 33 years and above. The respondents in the first and second groups (78\%) outnumbered those in the third and fourth groups (21\%).

Educational qualifications: 148 respondents are graduates and 35 respondents are post graduates and 16 of them completed another pre-university. From this we can see that all the respondents are educated well.

Occupation: $58 \%$ per cent of the respondents are students and 30\% respondents are employed in a private sector, $7 \%$ of the respondents are government employed and remaining $5 \%$ are self-employed. Clearly the maximum of respondents belong to student community.

\section{SECTION-2}

Media usage and gratification

Table 1

\section{Frequency of TV usage}

\begin{tabular}{|c|c|c|}
\hline Particulars & Respondents & $\%$ \\
\hline 30 minutes -1 hour & 42 & 21 \\
\hline 1-2 hour & 70 & 35 \\
\hline 2-3 hour & 48 & 24 \\
\hline More than 3 hours & 36 & 18 \\
\hline Total & 200 & 100 \\
\hline
\end{tabular}

The data as revealed in Table 1 shows that most of the youth prefer watching television for 1-2 hours, followed by 2-3 hours. This statistic data underscores previous studies happened in this regard as majority of the youth unlike whether they are studying or employed find at least 1-3 hours for TV viewing, this also reiterates the attachment of youth to television.

Table 2

\section{Preference over various types of channels}

\begin{tabular}{|c|c|c|}
\hline Particulars & Respondents & $\%$ \\
\hline Entertainment & 82 & 41 \\
\hline Music & 33 & 16.5 \\
\hline News & 59 & 29.5 \\
\hline Cartoon & 10 & 5 \\
\hline Sports & 13 & 6.5 \\
\hline Others & 3 & 1.5 \\
\hline Total & 200 & 100 \\
\hline
\end{tabular}


From the Table 2 it is evident that the maximum respondents prefer watching entertainment channels (41\%). Few respondents showed interest in watching music (16.5\%) and news channels (29.5\%) followed by cartoon, sports and other channels of their interest which contains both regional and international channels especially for sports, music, cartoon, and news.

Table 3

Types of programmes preferred watching

\begin{tabular}{|c|c|c|}
\hline Particulars & Respondents & \% \\
\hline News & 79 & 39.5 \\
\hline Music & 11 & 5.5 \\
\hline Cinema & 13 & 6.5 \\
\hline Serials & 18 & 9 \\
\hline Reality shows & 73 & 36.5 \\
\hline Spiritual & 0 & 0 \\
\hline Educational & 3 & 1.5 \\
\hline Others & 3 & 1.5 \\
\hline Total & 200 & 100 \\
\hline
\end{tabular}

Most of the respondents prefer watching news (39.5\%) on TV apart from news. It is the reality shows (36.5\%) that caught the attention of the youth, even serials, cinema and music have smaller percent of viewers. As for cinema (6.5\%), youth prefers watching regional, national and international movies. When it comes to viewing reality shows, youth generation chooses watching regional and national reality shows which are the local versions of the international shows. E.g.: Voice of America (a similar Indian show is called Voice of India); Big Boss and Master Chef Shows, Dance shows, Talent shows, etc.

Table 4

Preference over foreign and Indian channels

\begin{tabular}{|c|c|c|}
\hline Particulars & Respondents & $\%$ \\
\hline Foreign channels & 93 & 46.5 \\
\hline Indian channels & 107 & 53.5 \\
\hline Total & 200 & 100 \\
\hline
\end{tabular}

Out of the total 200 respondents 107 which is about 53.5\% prefer watching Indian channels. 93 respondents which is about $46.5 \%$ of the total sample size prefer watching foreign channels. This statistic data shows that number of transnational channels viewers has increased considerably. 
Preference of respondents over various channels

\begin{tabular}{|c|c|}
\hline Particulars & Respondents \% \\
\hline Suvarna & 89 \\
\hline Chandana & 23 \\
\hline Doordarshan & 12 \\
\hline U2 & 64 \\
\hline Udaya & 103 \\
\hline Kasturi & 73 \\
\hline MTV & 103 \\
\hline Sony TV & 69 \\
\hline STAR PLUS & 93 \\
\hline STARGOLD & 79 \\
\hline ZEE Kannada & 72 \\
\hline ZEE TV & 79 \\
\hline V Channel & 98 \\
\hline
\end{tabular}

Respondents were asked to choose the channels which they used to watch from a list of selected channels. Here the channels are selected on the basis of the objective of the study that is to trace the impact of globalised TV on youth. The respondents are given a list channels which can be considered as glocalized. From the data we can see that majority of the respondents prefer watching MTV, SONY TV, Udaya, Zee TV, V channel. All these channels are good examples of glocalised TV channels.

\section{SECTION-3}

Effects amounting from the medium

Table 1

Preference of food items seen on TV

\begin{tabular}{|c|c|c|}
\hline Particulars & Respondents & $\%$ \\
\hline Yes & 133 & 66.5 \\
\hline No & 67 & 33.5 \\
\hline Total & 200 & 100 \\
\hline
\end{tabular}

The respondents were asked whether they prefer to buy the food items which they have seen on TV. 133 out of 200 respondents which is about (66.5\%) of the total sample size prefer buying the food items which they have seen on TV. 
While 67 of them (about 33.5\%) do not prefer buying. From this we can see that the respondents' food habits are influenced by television.

Table 2

\section{Preference of dress/apparel seen on TV}

\begin{tabular}{|c|c|c|}
\hline Particulars & Respondents & $\%$ \\
\hline Yes & 143 & 71.5 \\
\hline No & 71 & 35.5 \\
\hline Total & 200 & 100 \\
\hline
\end{tabular}

The data as revealed in the Table 2 shows that most of the respondents (71.5\%) prefer buying the dress/apparels seen on TV. This clearly tells us that television plays the key role in people's dress code which they imitate and adapt from the global level to the local one.

Table 3

Imitation of hair style/ mannerism seen on TV

\begin{tabular}{|c|c|c|}
\hline Particulars & Respondents & $\%$ \\
\hline Yes & 117 & 58.5 \\
\hline No & 83 & 41.5 \\
\hline Total & 200 & 100 \\
\hline
\end{tabular}

Respondents were asked a question, whether they prefer imitating the TV idols' hair styles, mannerisms. Out of the 200 respondents, 117 which is about (58.5\%) said they do prefer imitating while 83 respondents $(41.5 \%)$ said they do not prefer. From this data it is evident that the television definitely shapes people's mannerisms.

Table 4

\section{Preference of branded products}

\begin{tabular}{|c|c|c|}
\hline Particulars & Respondents & $\%$ \\
\hline Yes & 149 & 74.5 \\
\hline No & 51 & 25.5 \\
\hline Total & 200 & 100 \\
\hline
\end{tabular}

The respondents were asked if they prefer buying branded products, 74.5\% of the respondents replied yes, while 25.5 said no. That means majority of the respondents give preference to the concept of brand while buying a product. 
Motivational medium behind choosing a brand

\begin{tabular}{|c|c|c|}
\hline Particulars & Respondents & $\%$ \\
\hline TV & 143 & 71.5 \\
\hline Radio & 4 & 2 \\
\hline Newspaper & 23 & 11.5 \\
\hline Internet & 30 & 15 \\
\hline
\end{tabular}

The respondents were asked from which medium they get the idea of a particular brand. $71.5 \%$ of the respondents get the idea of brand from television followed by $15 \%$ from the Internet and $11.5 \%$ from newspapers. The global brands are available in cities like Bangalore, which is more cosmopolitan in culture, and people are exposed to various forms of media.

\section{SECTION-4}

\section{Purpose behind using the medium}

Table 1

\section{Purpose of TV viewing}

\begin{tabular}{|c|c|c|}
\hline Particulars & Respondents & $\%$ \\
\hline Entertainment & 40 & 20 \\
\hline Education & 30 & 15 \\
\hline Information & 28 & 14 \\
\hline All of the above & 102 & 51 \\
\hline Total & 200 & 100 \\
\hline
\end{tabular}

According to $20 \%$ of the total samples, the purpose of TV viewing is entertainment, $15 \%$ among the respondents opinionated that they use television for educational purposes and $14 \%$ television viewing is for information. However, the majority (51\%) prefer watching television for all of the purposes above.

\section{Discussion}

The study reveals that television is still the most preferred medium of the youth, even at the time when new media has thrown up plenty of useful options and amenities. Majority of the youth dedicates daily 1-3 hours to watching television. The finding will be interesting when one connotes it with the fact that Bangalore is a metropolitan city and IT capital of the country. This also underscores the attachment of youth to television. 
From the analysis we can see that the majority of youth spent their time on watching entertainment programmes. Other than news, the main programme the youth prefer watching is a reality show. Serials and music programmes also have a good number of viewers. Reality shows which run on Indian television are adapted versions of the ones which appear on foreign television channels or, as we can call them, 'globalised' programmes. Consequently, from the study it is evident that the youth are making use of globalised programmes that entertain them well. From the analysis we can see that the youth prefer watching Indian channels rather than foreign channels.

The channels which Bangalore youth prefer watching are MTV, V-channel, STAR, ZEE, etc. These channels can be considered the perfect manifestation of glocalisation. The content of these channels is global in spirit, but local in nature. If the youth prefer watching such channels intentionally, they are enamored by the content of that channel or they like enjoying the glocalized programmes. From the first part of the analysis it has been understood that the youth are making use of the glocalised channels and their content.

The third part of the analysis is pertaining to the effects amounting from the medium or the level of its influence. The majority of youth prefer buying the food items and apparels seen on TV. Food habits and dress code are part of one's culture. Culture in this context is the culture which is followed by the people of a particular place. Hence, the study shows that television alters the culture. The television thus redefined the parameters of the prevailed culture among the televised youth. The analysis revealed that the youth are interested in following the mannerisms and hairstyles, etc. of the TV idols. This finding demonstrates the slow and steady proliferation of globalised culture among the youth.

From the analysis we can see that the youth are enamored of the 'brand' concept. The brand can be one of the byproducts of globalization, which makes the 'brand' concept more 'palatable' to the third world countries like India; the youth have been influenced by the television and, as a result, have become ardent followers of 'brand'. From the study we can see that television has made the concept of brand popular among youth rather than newspapers and the Internet.

The youth make use of the medium television mainly for the purpose of entertainment followed by education and information, the second and third parts of the analysis together give the idea that the attitudinal change amounting from the globalised television is positive, the youth consider television as the medium for infotainment and education and they try to copy content in their real life. Since the users use a medium for education and use new knowledge and skills in their real life, that would definitely have positive impact on their life. 


\section{Conclusion and recommendations}

The study focuses on how globalisation has adapted to a new culture to suit local tastes, leading to the phenomenon called glocalisation. The youth prefer watching more foreign channels in local languages as it makes them better understand a new culture modified in a local way, thus introducing the theory of globalisation and glocalisation stronger. The respondents of the present study enjoy the cuisines from other countries which are extremely popular all over the world but love them more in a local interpretation. Today, we also see our national versions of burgers and pizzas that become more popular if they have more local spices among the ingredients.

The study tried to understand the impact of globalisation and glocalisation in terms of food, clothes, styles, etc. The study focused only on the impact of its adaptation on youth generation in Bangalore city. It does not state the negative aspects of the global-glocal culture nor did it ask about any negative state of the impact. In the future, the research may reveal the negative aspects of globalisation among local cultures.

As television is still one of the most influential types of the media, the study has many objectives that are to give an insight on how youth make use of TV as one of the major mass media, their reasons for watching TV and cultural change amounting from the medium. The outcome of the study has brought some newsworthy results: globalised television is being utilized efficiently to inform, to educate, and to entertain in a healthy way.

Apparently, TV has created cultural acceleration through its consummate artistry. People, especially the youth, graciously and gracefully accept the programmes disseminated by television. The study reveals that Indian television is under the clutches of glocalization. Glocalized television is imparting an intractable and ostensible cultural change. Youth of our country are enamored by the programmes of the glocalized television, try to accept and bring its content into their life. Glocalization was successful in bringing the essence of globalisation in a locally acceptable way. The study has thrown light on the fact that youth have taken the concept of glocalization positively and effectively carry out its implications in their everyday life.

As mentioned before, more detailed studies of glocalization and its impact on culture have not been conducted. In India, sociologists and social science researchers need to shift their focus to glocalized culture, which would have definite results in some noteworthy findings. Obviously, glocalization plays a complicit role in shaping our culture so as to fit according with the changing trends and technological advancements. Also, there is need for an elaborate study on the negative effects of glocalization, this will definitely open up new 
discussions and debates. This study recommends further in-depth research in the area of glocalization and cultural transformation.

\section{References}

APPADURAI, A. (1996). Modernity at large: Cultural dimensions of globalisation. Minneapolis, MN, University of Minnesota Press.

APPADURAI, A. (2003). Disjuncture and difference in the global cultural economy. In: L. Parks \& S. Kumar, Planet TV: A global television reader. New York, University Press, pp. 40-52.

BAKSHI, M. \& SARKAR, S. (2015). 'Crazy Kiya Re': Explaining the consumption and popularity of Hindi film songs. South Asian Popular Culture, 13(2), pp. 141153. DOI: $10.1080 / 14746689.2015 .1088497$.

GIDDENS, A. (1990). The consequences of modernity. Stanford CA, Stanford university press.

GOPAL, S. (1994). Television in India - changes and challenges. New York, Vikas Publishing House, Pvt. Ltd.

HOFSTEDE, G., HOFSTEDE G. J. \& MINKOV, M. (2010). Cultures and organizations: Software of the mind. New York, McGraw-Hill.

JONES, S. (2005). MTV: The medium was the message, critical studies in media communication. Journal of Critical Media Studies, 22(1), pp. 83-88. DOI: $10.1080 / 0739318042000333734$

JULURI, V. (2002). Music, television, and the invention of youth culture in India. Television \& New Media, 3(4), pp. 367-386. Available from: https://doi. org/10.1177/152747602237283

KATZ , E., BLUMLER J. G. \& GUREVITCH, M. (1973). Uses and gratifications research. Public Opinion Quarterly, 37(4), pp. 509-523.

KEVAL, K. J. (1981). Mass communication in India. New Delhi, Jaico Publishing House.

KUMAR, K. \& PRASAD, S. (2008). Gratifications and media use: An analytical study among Omani youth. Journal of Mass Communication, Dharwad, Karnatak University.

RANGANATHAN, M. \& RODRIGUES, U. M. (2010). Indian media in a globalised world. New Delhi, Sage.

ROBERTSON, R. (1992). Globalisation: Social theory and global culture. London, Sage.

TOMLINSON, J. (1999). Globalisation and culture. Cambridge, Polity Press.

VIJAYALAKSHMI, P. (2004). Foreign television and Indian youth - changing attitudes. New Delhi, Concept publishing company.

WAISBORD, S. (2004). McTV: Understanding the global popularity of television formats. Television \& New Media, 5(4), pp. 359-383. Available from: https://doi.org/10.1177/1527476404268922 